\title{
Fundamental Studies Based On Metal Heat Treating Processes \& Forming Technology - A Review
}

\author{
Pranav Kumar ${ }^{1}$ \\ ${ }^{1}$ Shri Mata Vaishno Devi University, School of Mechanical Engineering, \\ Hospital Road, Kakrayal, Jammu \& Kashmir \\ kumarpranav9510[at]gmail.com
}

\begin{abstract}
In this review paper which is based on the recent studies of heat treatment processes in metal forming technology, will light upon the basics of the heating processes and the fundamental principles of those heating phenomenon, basic principle \& important application's in metal forming technology, some industrial and manufacturing heat treating techniques are also discussed in this review research on metal forming technology. Latest investigations and recent studies have been made of the hardening and heat treating of metal to obtained in annealed crystalline aluminum by changing characteristic's like stresses, strain etc at various instants, to obtain pure failure and various different desired results of hardening and softening thus, to enhance the profound knowledge of the heat-treating processes and its characteristic's this small review describing the desired results for the enhanced and effective results in the engineering practice.
\end{abstract}

Keywords: Heat Effectiveness, Composition, Grain Structure, Aluminum, Automobile, Metal alloy, Hardening.

\section{Introduction}

The term heat treatment processes in metal forming technology refers to the industrial and metal working processes which are widely used to show the variations and the fundamental change in the properties of that particular material or embodiment specimen unit. A great variety of experimental conditions has been used in today's heat treatment processes where hardening and softening of metal is done by cyclic stressing. [1] Heat treatment processes in metal forming technology is generally used to make the alteration in the chemical and physical embodiment properties of the metal or a specific material which is used and utilized for the manufacturing and engineering practice. Thus, it is very important to understand the fundamentals of the heating treatment processes and its basic fundamental principles which will help us to maintain the overall strength and to achieve a desired result such as softening and hardening of that particular metal or any material.

\section{Heat Treatment Processes}

Heat treating is a phenomenon of industrial \& manufacturing metal forming (Metal Working) processes in which the physical and the chemical properties of any material is altered and organized along the need and requirement in the industrial or any commercial activity, is what we study in in the heat treatment processes.

Following are the fundamental heat-treating processes which are widely used for the hardening and therefore the softening of the material:

- Annealing

- Case Hardening

- Tempering

- Quenching

- Normalizing

- Precipitation Strengthening

\section{- Decarburization}

Above mentioned are the famous and are the most attentiongrabbing heat-treating processes which are widely used for the various (Hardening \& Softening) purposes and various application use to enhance the rate of production and industrial activity. Full detailed analysis of the above heattreating processes will be discussed later in the paper with the help of proper analysis of the material and its variations along the different directions of that embodiment material on which the analysis has been carried out. Thus, it will help us to analyze \& study the various changes along different directions in the material properties.

While studying heat treatment processes as an application of Mechanical system we get to know more about the fundamental and physical characteristics of the material (Metallic Alloy), as it shows the variation, if the chemical as well as the physical composition of the structure is changed by the means of different heat treatment processes, we observe a variation along its characteristics and its properties. Which will affect the mechanical behavior of the material or any Metallic alloy which is used for the engineering practice or for any other commercial purpose.

\section{Study of Physical Processes}

The physical processes in heat treating can be well knowledged by studying the various characteristics of the alloys and its various properties on which the alteration can be carried to obtain the desired and the most effective results in the material. The crystal structure consists of atoms that are grouped in a very specific arrangement, known by name lattice. In most elements, this order will rearrange itself, depending on conditions like temperature and pressure. This rearrangement, named polymorphism, may occur several times in any particular system of arrangements, at many different instants of temperatures for a particular metal or alloy. In alloys, this rearrangement may cause an element that

Volume 6 Issue 12, December 2017 


\section{International Journal of Science and Research (IJSR) \\ ISSN (Online): 2319-7064}

Index Copernicus Value (2016): 79.57 | Impact Factor (2015): 6.391

will not normally mix and dissolve into the base metal to suddenly become mixable and soluble, while a reversal of the allotropy will make the elements either normal or completely insoluble. [3]
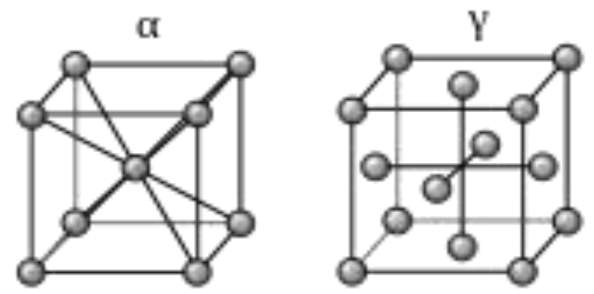

Figure 1: Illustrates the allotropes of iron as, $\alpha$-Iron (Low Temperature), $\gamma$-Iron (High Temperature)

In the above figure. 1 which shows the allotropic forms of the iron in which the different conditions are followed and studied to ensure the desired results and the desired variations in the mechanical behavior of that alloy, as $\alpha$-Iron shows that the no spaces or carbon atoms to reside along the body structure, while $\gamma$-Iron shows that the carbon atoms are free to show the movements along the lattice structure of the embodiment small carbon atom. [4]

As studies show that if the heat treatment processes are being carried out by means of the variations in the Mechanical System or Mechanical Behavior thus, the variation in the following properties can be observed are as followed below-

- Hardness

- Toughness

- Ductility

- Elasticity

- Strength hardening

- Creep

Thus, the behavior of the material changes whenever it is processed by any heat-treating processes as discussed above in the review thus, various change in the mechanical properties can be observed and can be studied to get the desired results. In metal forming Technology all the metallic materials consist of some small crystals which are usually well known by means of "Grains" or small crystallites. The most effective and the enunciating property that can determine the overall change in mechanical behavior of metal is nature of grain and composition. Though, it is very important to study the various physical processes of heat treating processes to enhance the knowledge of the metallic alloys, manipulating properties of the metallic alloys and the properties with which the physical and sometimes the chemical properties show changes along with the embodiment unit.

Study of physical processes in heat treating usually involves the variation and the manipulation of the mechanical properties by different methods and mechanisms that may change the fundamental properties of the alloy's while performing the heat-treating processes in metal forming technology.
The most common and the widely used mechanisms that can help to change the properties of the metallic alloys during heat treating processes are as followed below:

- By controlling the rate of the diffusion mechanisms.

- By controlling the rate of cooling within the microstructure.

- By formation of martensite.

These are the most famous methods of heat treating phenomenon in which the change in the homogeneity of the alloys can be formulated \& carried out which results into the change in the behavioral changes in the mechanical properties of the metallic alloy or any other material. As the above processes are occurred due to the formation of the martensite which directly causes the deformation of the crystals of material alloy intrinsically (natural way). As on the same way the control rate of the diffusion mechanisms can cause the variations in the homogeneity of the alloy (Metallic alloy).

\section{Studies on Heat Treatment Processes}

Recent studies on heat treating processes illustrates that the heat treatment is a controlled process which is used to alter the microstructure of material or of any specimen, such as alloys and metals which imparts the fundamental properties, which directly enhances the working ability as well as the working life of the material or any component. Such as increased surface hardness, ductility, temperature and strength. Thus, the explained study is strictly on the primary heat-treating processes as mentioned above in the section 3 ,

Now, the manufacturing process considered is the heat treatment of steel casting parts. This is actually a sub-process of the entire steel parts casting which includes sub-processes like melting, machining, grinding, cutting and cleaning and heat treatment [2]

As some of them (Major Processes) has been explained with respect to the recent studies which are as followed below-

\subsection{Annealing}

Annealing in material science \& metal forming is a stress relieving phenomenon in which the material or a specimen is heated at a temperature above its upper critical temperature thus the increase in the ductility and decreases in the hardness of a material is observed is known as annealing process.

\subsection{Normalizing [8]}

Normalizing in metallurgy \& metal forming is a grain refining process $\&$ it is a profound technique which is widely used to provide the uniformity in the grain size (microstructure) and composition of any metallic alloy, this process is as similar as annealing but the main difference in between them is the method of cooling the material or an alloy throughout the whole process phenomenon thus, in normalizing the cooling is usually carried out in air but as in annealing it is done by the furnaces itself. It produces 


\section{International Journal of Science and Research (IJSR) \\ ISSN (Online): 2319-7064}

Index Copernicus Value (2016): 79.57 | Impact Factor (2015): 6.391

martensite and sometimes bainite, which gives harder and stronger steel than other, but with less ductility for the same composition of metal alloy than full annealing process.

\subsection{Hardening}

Hardening in metal forming \& material sciences illustrates that the process of heating of the material or specimen alloy under well above the upper critical temperature which on the other hand increases the wear resistance \& Higher resistance to plastic deformation of the material and the hardness of the metallic alloy or ant material will get increased and enhanced by adopting the method of cooling of material alloy (or any materiallspecimen) by means of quenching, we will discuss this term later in the section 4.4 .

\subsection{Tempering}

Tempering in material sciences is the process of heating the material or metallic alloy well below the lower critical temperature of material. In steels, it is often from (400 to $1105{ }^{\circ} \mathrm{F}$ ) or (205 to $595{ }^{\circ} \mathrm{C}$ ), depending upon the desired values and the results obtained, thus to impart the toughness by heating the material and then by cooling it in the air is called as tempering.

\subsection{Quenching}

Quenching is a fundamental process of rapidly cooling the material parts or steel alloy parts from austenizing and solution treating temperature, within the range of (815 to 870 $\left.{ }^{\circ} \mathrm{C}\right)$, (1500 to $\left.1600{ }^{\circ} \mathrm{F}\right)$ in case of the steels, the results of quenching generally dependent on the material composition, type of quenchant, or the quenchant use condition across the embodiment structure of material. The rate of heat extraction from the specimen is generally depends on the different type of quenchants used and different type of quenching process adopted for the cooling purpose or for the heat extraction purpose thus following are some of the basic quenching techniques which imparts the quenching performance and the variation in the quenching practice which is being carried out for the desired results.

Some of the specific quenching techniques are as named below-

- Direct quenching Method

(Slow cooling is Practised)

- Time quenching Method

(Time domain cooling is Practised)

- Selective quenching Method

(Slow cooling by Quenchant contact)

- Spray quenching Method

( High Pressure Steam of Quenchant Liquid)

- Fog quenching Method

( Spray Quenching is Practised)

Thus, the specific quenching techniques are well explained and detailed above in the points thus to clear the heat extraction phenomenon from the material in metal forming technology. It is very important to understand the phenomenon of heat extraction from the particular specimen thus to obtain the desired results and output for the engineering practice

\section{Effect of Composition \& Grain Structure}

Thus, now we are well aware about the recent studies and the profound knowledge of the major heat treatment processes which mainly describes and throws light on the concept of the grain structure of the material, thus we get to know that if some material is treated with some heat-treating process thus it imparts the change in the grain structure of the material and as well as on the chemical properties of that particular material. Thus, the property of the material or the substance is the function of its grain structure, therefore refined grain structure implement's that the better reliability and the strength after the processing of the heat treatment process.

The specific composition of an alloy system will usually have a great effect on the obtained results of heat treating. If the percentage of each constituent is just right, the alloy will form a single, continuous microstructure upon cooling. Such a mixture is said to be eutectoid mixture. However, If the percentage of the solutes varies and show change from the eutectoid mixture, two or more different microstructures will usually form simultaneously in the embodiment unit of mixture. A hypo eutectoid solution contains less of the solute than the eutectoid mixture, while a hypereutectoid solution contains more and is more effective than the other [9].

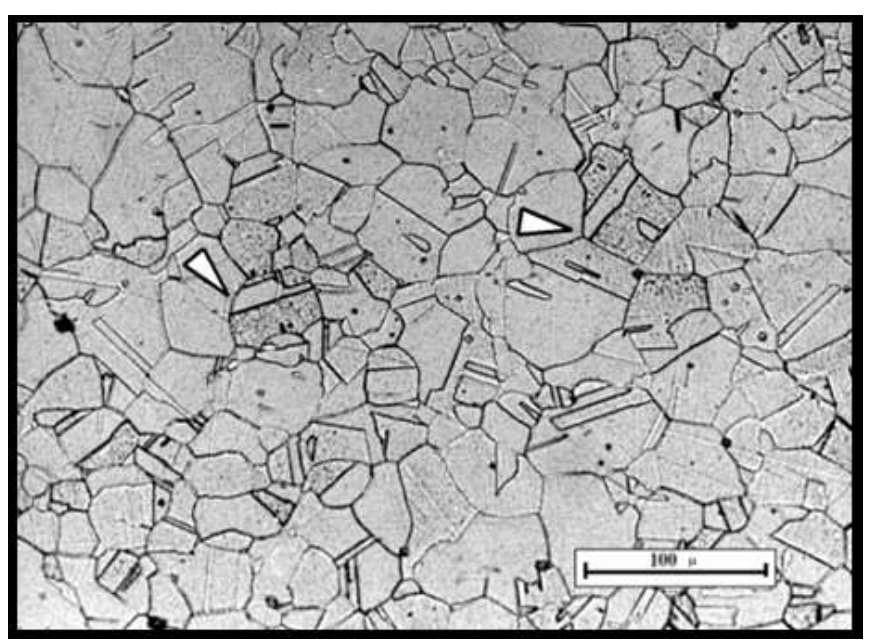

Figure 2: Illustrates the Microstructure \& The Grain Structure of the Austenitic Stainless Steel

As the above figure. 2 shows the fundamental microstructure of the austenitic stainless steel and the grain study is also being shown in the above illustrated figure to give the profound view of the microstructure under various ambient conditions. Now the question arises that what is austenitic stainless steel as this is a wide term, usually and mostly is well studied in the Iron-Carbon Equilibrium diagram which is well explained in the below case study. Thus, above the grain structure of an austenitic stainless steel is being observed and studied with the help of the light microscopy on a particular specimen polished and by coating it with a protective layer electrolytically using $15 \%$ oxalic acid solution in water or liquid. Though by achieving this we observe that many of the 


\section{International Journal of Science and Research (IJSR) \\ ISSN (Online): 2319-7064}

Index Copernicus Value (2016): 79.57 | Impact Factor (2015): 6.391

grain contains the annealing twins they are formed due to low alloy steel. The above shown steel in the figure is widely used in the construction of highly sophisticated \& cumbersome power generation embodiment units.

Thus, from all of the above results and studies so far, we get know the importance $\&$ as well as the basic knowledge of the heat-treating processes in metal forming technology, which are very important in our daily industrial routines and in daily engineering practices thus, to obtain the desired results for the embodiment unit of material alloy. Now on the basis of the recent studies on heat-treating phenomenon, various different case studies are profoundly discussed in the below section thus to get the perfect and the sharp application based knowledge of the heat-treating process.

\section{Case Studies Based on Heat Treating Processes}

In this section, we will discuss the different case studies based on the heat-treating processes and the recent studies on these cases which results into a profound desired results and analysis of such embodiment system study. Thus, these studies will help all of us to encourage the recent inventions and betterments in the heat treating on materials in various different fields of engineering.

\section{Emerging Effects of Heat-Treating on Materials Used in Automobiles Vehicles: A Case Study}

\subsection{Basic Idea}

Automotive industries are one of the most utilized and emerging sector in today modern world, where many different materials are manufactured and made to work effectively and efficiently, thus the need of hour and the demand require automotive industries to be more environmental friendly, responsible, effective and fuel efficient with respect to their products manufacturing and processes management in the automotive industry, reasons include regulatory requirements of the material in the industry, public demand, and potential competitive advancements in the industry. The automobile industry is among the sectors that have been hit most by the recession. Demand for cars fell sharply, accentuating the difficulties of excess production capacity already faced before the crisis and deepening the economic downturn in major carproducing countries. Relative to the general downturn, the decline in car sales was nonetheless not deeper than what was observed in the past. [5]

In this review of case study, basic and fundamental of the effects of the heat treatment on material utilized in the automobile engineering, the most utilized and used materials are aluminium and steel, thus we will study and address the important application of such type of materials and the various different types of benefits of heat treatment on these metals like aluminium and steel. And it is very important to discuss the various stresses upon the application of same in automobile engineering. These specific studies can be helpful and can make work easy and simple to engineering and automobile industry associates as they respond to environmental and recent demands \& needs assuring quality control and assuring various demands and mechanization of the industries.

In the recent studies, it has been observed that there has been rapid growth in road transportation in today's modern era, and this transportation activity is set to continue for the longterm future. As we know that today's transportation is based on the regular consumption and regular utilization of petroleum products in various engineering practices such as gasoline and diesel, and inversely it is responsible for the generation of various gases such as (CO2) emissions. In recent years vehicles have shown several various fundamental changes towards the sustainable environmental conditions and thus the transportation activity has been developed and undergone various enhanced developments which reduced the emissions, some of these changes are as followed below;

- Matter of Technology developments

- Industrialisation

- Cost optimisation

- Activities concerned by government interventions

- Emission control.

Modern industrial activities and operations in automobile sector generally faces environmental and economic pressures which affect the mechanical behaviour of the material such as:

- Efficient \& Effective use and management of resources

- Effective use and management of Energy.

- Emissions Reduction,

- Process Reliability

These above-mentioned challenges can only be improved by constantly working with the recent studies and recent methods and process technology. In automobile sector, the main methods and the process technology are improved heat treatment processes which increases the strength and the toughness properties of metallic structural components of the material thus variation in the mechanical properties and modern surface engineering technologies and recent researches reduced the effects of abrasion in automobiles.

\subsection{Heat Treatment \& Its Various Effects}

Heat treatment is a controlled process which is widely used to alter and change the physical, chemical properties and sometimes the microstructure of materials such as metals and alloys to implement various aspects of properties which directly improves and enhances the working life of a component and as well as the material used, let us take some examples which will help us to understand the above statement

1) Increased Surface Hardness of Material.

2) Temperature resistance of Component

3) Ductility of the Material Used

4) Strength of the Component

\section{Volume 6 Issue 12, December 2017}




\section{International Journal of Science and Research (IJSR) \\ ISSN (Online): 2319-7064}

Index Copernicus Value (2016): 79.57 | Impact Factor (2015): 6.391

S.M. Afazov et al. (2012) stated that medium hardenability steel obtains excellent strength and mechanical properties after heat treatment, and the machinability of 4140 steel is much better. [4], There are various different types of heat treating processes major ones being well discussed above in the Section 4 such as annealing, normalizing, tempering, hardening and quenching.

\subsection{Recent studies \& Considerations in Automobile material}

As we all are well aware about the automobile industries that since from 19 century this field of engineering is dominated by the steel, which is widely used for the manufacturing of the parts of the automobile. From the past few years, as we known that the automobile sector undergone various changes in terms of materials utilized for the manufacturing of the various parts of the automobile. As we know, now a day the manufacturing industries are widely using and utilizing aluminium as a manufacturing material which is very subtle and has various advantages and benefits which directly helps to improve the overall performance \& the efficiency of the automobiles.

A modern automobile which is profoundly manufactured with components made of aluminium are observed to be very lighter than the components and the parts made of steel, which directly enhances and improves the fuel consumption efficiency of the automobile. Usually it is reduced by $2 \mathrm{~L}$ per $100 \mathrm{~km}$, which automatically help the vehicle to maintain and reduce the harmful gases such as like $\mathrm{CO} 2$ and $\mathrm{CO}$. Advanced studies on this material results into the high-tensile aluminium alloys which can now completely replace steel in manufacturing industries.

Now we will discuss the past trends in the weight of passenger car \& material of a typical passenger car is followed in the below table

\subsection{Trends in Weight \& Materials of a Typical Automobile}

Table 1: Trends in Weight of Material in Automobile

\begin{tabular}{|c|c|c|c|c|c|c|c|}
\hline $\begin{array}{c}\text { Modal of } \\
\text { Automobile }\end{array}$ & $\begin{array}{c}\text { Weight } \\
(\text { Kg })\end{array}$ & $\begin{array}{c}\text { Iron \& } \\
\text { Steel }\end{array}$ & $\begin{array}{c}\text { Cast } \\
\text { iron }\end{array}$ & $\begin{array}{c}\text { Non- } \\
\text { ferrous }\end{array}$ & Rubber & Plastic & glass \\
\hline 1968 & 1020 & 75 & 11.8 & 5.0 & 3.6 & 2.6 & 3.0 \\
\hline 1978 & 1144 & 75.7 & 10.1 & 7.8 & 3.0 & 3.0 & 2.4 \\
\hline 1988 & 1300 & 73.7 & 10.4 & 7.2 & 7.1 & 7.1 & 2.6 \\
\hline 1992 & 1290 & 71.7 & 10.3 & 9.2 & 7.5 & 7.5 & 3.1 \\
\hline 1996 & 1313 & 69.8 & 10.2 & 10.4 & 9.2 & 9.2 & 2.9 \\
\hline 2000 & 1371 & 68.7 & 8.2 & 10.6 & 9.0 & 9.0 & 2.6 \\
\hline
\end{tabular}

The above table 2.5 shows the trends in weight of different materials in a typical automobile over the passing of years. And the most attention-grabbing change which can be observed is that the increase in the weight of the automobile car, the $\%$ of the steel has been changed and observed to be decreased with respect to the material used while manufacturing, on the other hand the composition of nonferrous material which is aluminum has shown a large increase in the material properties over the years.
Indeed, any analysis of trends in the auto industry needs to stress that the industry faces a major-but long-runtransition to new fuels, driven by both the need to shift to low-carbon systems so as reduce greenhouse gas emissions and likelihood of high energy prices linked to supply constraints (peak oil) and growing demand from emerging economies. [6]

\subsection{Experimental Analysis of Aluminium}

An experimental analysis was conducted to illustrate and show the various different and the fundamental effect of heat treatment on materials used in automobile vehicles. Thus, the metal on which the experiment is carried out is aluminum and its alloys because of its enhanced behavior and effective results in automobile industries, the hardness reading analysis of the material was taken prior to the conditions and after the heat treatment to observe the changes and the significant analytical values occurring in its behavioral properties such as hardness etc. Thus, to justify the statement and the desired results of analysis, though the aluminum is largely utilized and used for the manufacturing purposes in the engineering practice.

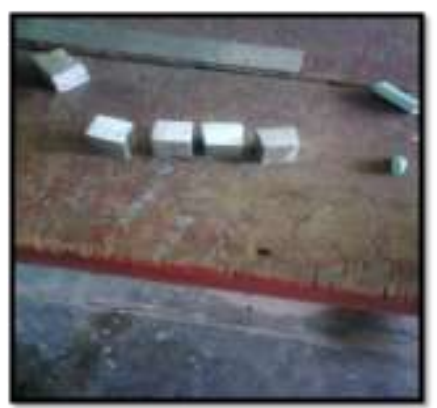

Figure 2: Illustrates the aluminum alloys pieces.

Aluminum is one of the most famous metal in today's world, as it is widespread in nature and is widely used for the industrial applications in engineering practice. Aluminum is a soft metal thus; the physical characteristics and chemical composition of this material makes it more lighter metal also. Though with a roughened coating of silver tint due to a thin oxide film of aluminum, which directly protects the metal from contact with air.

As the oxide film which is frosted of silver due to the oxides, makes aluminum more resistant to corrosion, and also it enhances the mechanical behavior of the aluminum, which directly imparts the strong and very long-lasting results, which directly reflects that the life of materials which are specifically manufactured with the composition of aluminum is very effective \& Efficient. In addition, aluminum has very high and effective electrical conductivity, it has various effective mechanical properties which influences the use of this metal, thus it is non-toxic and it is simply reproducible and reprocess able in nature.

\subsection{Aluminium in Automobile Industry}

As the rapid improvement in globalization and industrialization leads the demand of the metals such as aluminum, which is the second most demanded and most

\section{Volume 6 Issue 12, December 2017}




\section{International Journal of Science and Research (IJSR) \\ ISSN (Online): 2319-7064}

Index Copernicus Value (2016): 79.57 | Impact Factor (2015): 6.391

used metal in the automobile industry in terms of percentage of the total weight percentage of car, various components of automotive vehicles are manufactured and are made with the help of aluminum such as suspension, cylinder blocks of the engine, the chassis and the other various parts of vehicle are made with this metal. It is observed that $1 \mathrm{~kg}$ of aluminum can help us to remove and reduce up to $2 \mathrm{~kg}$ of steel and cast iron in many areas of vehicle manufacturing and applications.

\section{Conclusion}

This small review document introduces about the case study on the heat-treating processes in metal forming technology and the various applications of these processes under which the different type of materials and metals are processed to get the desired results and output as per as the requirement and the need of industry, This small dedicated study review confirmed the following major key points-

- Theoretical analysis of the heat treatment of materials illustrated the various changes in the behavior and in mechanical properties which depends on the heat treating of the particular material.

- Experimental analysis predicted the defects in the material and chemical modifications results in the increase or decrease in the mechanical behavior of the material.

- Case studies are discussed above in the review to get the information regarding the processing of the particular material like aluminum and the softening of steel is discussed.

- Overall in this review paper heat treating processes are demonstrated as an effective and the most powerful factor for variation in behavior of material as like friction and wear reduction in any mechanical system.

\section{References}

[1] T. Broom and R. K. Ham Proceedings of the Royal Society of London. series a Mathematical and Physical Sciences vol. 242, no. 1229 (oct. 29, 1957), pp. 166-179

[2] I. Mendikoa, M. Sorli, A. Armijo, L. García, L. Erausquin, M. Insunza, J. Bilbao, H. Friden, A. Björk, L. Bergfors, R. Skema, R. Alzbutas, T. Iesmantas, Heat Treatment Process Energy Efficient Design and Optimization, In Procedia Engineering, Volume 63, 2013, pp 303-309, ISSN 1877-7058,

[3] Robert W. Cahn, Peter Hassen, eds. (1996). Physical Metallurgy. Volume 2. Elsevier Sciences. Pp. 10-11.

[4] Khurmi R.S, Material Science, second edition, India, 2009

[5] X. Su, G. Wang, Y.T. Zhang, J.F. Li, Y.M. Rong, Modeling on Stress Evolution of Step Part for Castingheat Treatment Processes, In Physics Procedia, Volume 50, 2013, pp 360-367, ISSN 1875-3892,

[6] Haugh, D., A. Mourougane and O. Chantal, The Automobile Industry in and Beyond the Crisis, OECD Economics Department Working Papers, (2010)745

[7] Bailey, D., A. de Ruyter, J. Michie and P. Tyler, Global Restructuring and the Auto Industry, Cambridge Journal of Regions, Economy and Society, 3(2010) pp 311-318

[8] Dossett \& Boyer 2006, pp. 17-22
[9] B.B. Patra; Biswajit Samantray (2011). Engineering Chemistry I. Dorling Kindersley. pp. 75-77.

\section{Author Profile}

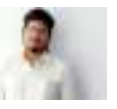

Pranav Kumar received the B. Tech degree in Mechanical Engineering from Rayat Bahra Group of Institutes, Ropar Campus "Punjab Technical University" in 2017 respectively, and perusing Master's (Manufacturing \& Automation) from Shri Mata Vaishno Devi University.

Volume 6 Issue 12, December 2017 